(C) 2015, Elsevier. Licensed under the Creative Commons Attribution-NonCommercialNoDerivatives 4.0 International http://creativecommons.org/licenses/by-nc-nd/4.0/ 


\title{
CONTEXT EFFECTS IN THE EVALUATION OF BUSINESS-TO-BUSINESS BRAND ALLIANCES
}

This is a pre-publication version. Please download the final version at: http://www.sciencedirect.com/science/article/pii/S0019850113001788

\author{
Stavros P. Kalafatis, Debra Riley, Jaywant Singh*
}

Professor Stavros P. Kalafatis; Kingston Business School, Kingston University, Kingstonupon-Thames, Surrey KT2 7LB, UK; Tel: +44(0) 208547 7121; email:

kalafatis@kingston.ac.uk

Dr Debra Riley; Kingston Business School, Kingston University, Kingston-upon-Thames, Surrey KT2 7LB, UK; Tel: +44(0) 208547 2000; email: d.riley@ kingston.ac.uk

Dr Jaywant Singh*; Kingston Business School, Kingston University, Kingston-upon-Thames, Surrey KT2 7LB, UK; Tel: +44(0) 208417 5158; email: j.singh@kingston.ac.uk

* Corresponding Author

Note: The names of the authors appear in alphabetical order 


\section{Author Biographies}

\section{Stavros P. Kalafatis}

Stavros P. Kalafatis is Professor of Business Marketing at Kingston Business School, Kingston University. His research focuses on business segmentation, design of channels of distribution, relationship marketing and value creation. His research has been published in, among others, European Journal of Marketing, Industrial Marketing Management, Journal of Business Research and Journal of Marketing Management.

\section{Debra Riley}

Debra Riley is a researcher at Kingston Business School. Her research focuses on marketing strategy, new product development and innovation. She has extensive experience in industrial sales and marketing. Her research has been published in the Journal of Product Innovation Management, Journal of Marketing Management, Journal of Business and Industrial Marketing and others.

\section{Jaywant Singh}

Jaywant Singh is Senior Lecturer in Marketing at Kingston Business School, Kingston University. His research interests are primarily in the area of consumer behaviour and branding. His research has been published, amongst others, in the Journal of Advertising Research, European Journal of Marketing, Journal of Business Ethics, International Journal of Market Research, Journal of Business and Industrial Marketing, and Journal of Strategic Marketing. 


\section{Research Highlights}

- We examine the managerial evaluation processes of $\mathrm{B} 2 \mathrm{~B}$ brand alliances using assimilation and contrast effects.

- Positive valence of the known brand ally results in higher evaluations of the brand alliance.

- Higher evaluations of brand alliances are the result of detailed information.

- Detailed information benchmarking tangible attributes of the alliance against other comparable offerings are more credible.

- Quality-related messages about an alliance's attributes that are difficult to be independently evaluated should be avoided. 


\section{CONTEXT EFFECTS IN THE EVALUATION OF BUSINESS-TO-BUSINESS}

\section{BRAND ALLIANCES}

\section{ABSTRACT}

Brand alliances in the business-to-business domain are becoming increasingly popular. This study investigates the impact of context-related effects on the formation of evaluation perceptions in B2B brand alliances. Assimilation and contrast effects represent the conceptual framework. Employing an experimental design we test the influence of two contextual factors on a range of product attributes: quality perceptions of the known brand ally (valence), and amount of information provided for the brand alliance. Using data collected from a cross section sample of large B2B UK companies we report assimilation effects across different product attributes of the alliance. Positive valence of the known brand ally results in higher evaluations of the brand alliance. In terms of provision of information, we find that, (a) unlike consumer markets, in the B2B domain higher evaluations are the result of detailed information, and (b) the impact of detailed information is significant only for tangible product attributes. Further, we find that valence of the known brand ally and amount of information provided are independent factors. The results add significantly to the knowledge on context effects in B2B brand alliances and lead to a number of managerial recommendations on partner selection and marketing communication of new brand alliances.

KEYWORDS: context effects, brand alliances, assimilation, valence, information, experiment 


\section{INTRODUCTION}

An increasing emphasis on branding activities is evident in B2B markets. Papers in the recent IMM special issue on branding (IMM, 2011) articulate the importance of branding in the B2B domain and provide commentaries on the benefits, implementation, and role of branding in B2B markets. The contributors to the IMM special issue concur in their assessment that, (a) much of the B2B literature is grounded on theories developed in $\mathrm{B} 2 \mathrm{C}$, (b) despite recently expanded academic interest, the field remains under-researched (especially compared to B2C branding), and (c) the related literature lacks systematic treatment, thus resulting in a fragmented body of knowledge.

Despite evidence of its application in a wide range of commercial activities, an area of B2B branding that remains under-researched is brand alliances, also referred to as co-branding. Brand alliances range from initiatives that present several brands in a single advertisement (e.g., Sony Ericsson and Carphone Warehouse), to cause-related brand alliances (e.g., Royal Mail Group and the Barnardo's children's charity), and dual-branded products (e.g., Flash with Febreze). Brand alliances benefit the partners through reputation endorsement and access to resources and competencies, such as distribution and technology (Cooke \& Ryan, 2000; Bengtsson \& Servais, 2005; Erevelles et al., 2008).

An examination of the brand alliance literature identifies only eight studies located in the B2B domain, as briefly discussed below. Norris (1993) presents a case study of Intel, highlighting the benefits of its component branding strategy of Intel-inside. Bucklin and Sengupta (1993) show that successful brand alliances involve partners with relatively equal power and managerial resources, while Dahlstrom and Dato-on (2004) indicate that both asymmetry and complementarity of company assets are positive determinants of a firm's decision to co-brand. Evidence of asymmetric benefits to the parent brands is confirmed by 
Bengtsson and Servais (2005) and Kalafatis et al. (2012) who report that customers predict greater benefits for the lesser known brand than its larger partner. An econometric model by Erevelles et al. (2008) reveals differential benefits to participants in vertical brand alliances, finding that upstream suppliers enjoy reduced competitive activity while downstream manufacturers are rewarded with a lower price. Ghosh and John (2009) use transaction cost economics to show that original equipment manufacturers are more likely to use branded components when the brand name of such components provides them with opportunities for significant market differentiation. Finally, Gammoh and Voss (2012) demonstrate that a company's propensity to engage in brand alliance activities is contingent on the extent and quality of related past experiences, managerial competence, and attitude toward brand alliance.

With the exception of Bengtsson and Servais (2005), Kalafatis et al. (2012) and Gammoh and Voss (2012), the above studies are grounded in economic theory while the other studies adopt inter-firm rather than customer perspectives. None of these studies focus on the mechanisms of evaluation of B2B brand alliances. Furthermore, despite research consistently highlighting the importance of brand-related attributes and conditions under which evaluations take place, these considerations are not addressed by related research (see review article by Leek and Christodoulides, 2011). Our study addresses the above by focusing on customer evaluations of specific (product) attributes, and examining the impact of context effects (i.e., conditions) on evaluations of brand alliances in the B2B domain.

According to Todorović (2010, p. 17), "Context effects are present when the perception of an object changes when its context changes, without any physical change in the object itself." The evaluation of an object (e.g., brand, product) is determined not only by its innate or true qualities, but also by the contextual factors or stimuli which, although external to the object, 
are present during the evaluation process (Huber, Payne \& Puto, 1982; Herr, 1986; Simonson \& Tversky, 1992; Dhar, Nowlis \& Sherman, 2000). The theoretical explanations of context effects are found in the accessibility and social judgement theories (e.g., Sherif \& Hovland, 1961; Higgins, 1996) which stipulate that evaluation, preference and decisions towards a focal object are influenced by or are functions of the contextual stimuli within which such activities take place (e.g., Simonson \& Tversky, 1992; Bettman, Luce \& Payne, 1998; Ha, Park \& Ahn, 2009). An illustration of context effects is provided by Norris and Colman (1996) who report that evaluations of the same advertisement (the object) differ depending on respondents' perceptions of involvement, entertainment and enjoyment related to the programme (the context) within which the advertisement is presented. Therefore context effects arise from the interplay between representations related to the object being evaluated and the accompanying contextual stimuli (Bless \& Greifeneder, 2009; Bless \& Schwarz, 2010).

Within the brand alliance literature the impact of context effects is discussed by Simonin and Ruth (1998, p. 32) who state that "judgments about the brand alliance are likely to be affected ... by the context of the other brand. The brand alliance stimulus information, presented through advertising or by experiencing it directly, accesses related affect and beliefs about those brands and products that are stored in memory." This perspective encompasses two elements, transfer of evaluation effects between brand allies, and contextual cues about the brand alliance. The above viewpoint is in line with Simonson and Tversky (1992) who consider that context includes not only characteristics of the choice set but also of the environment within which choices are made. In the B2C brand alliance studies, context effects are observed in the form of brand leveraging (Ghosh \& John, 2009), resource allocation (Heide \& John, 1990), feedback effect (Park, Jun \& Shocker, 1996), quality signals (Rao, Qu \& Ruekert, 1999), and are shown to affect preference for familiar stimuli 
(Simonson \& Tversky. 1992; Cook \& Mellers, 1998) and to help interpretation of unfamiliar stimuli (Wright \& Rip, 1980; Sen, 1998). However, despite advances in the consumer literature, research in the $\mathrm{B} 2 \mathrm{~B}$ domain is silent in terms of the role of context effects on evaluations of brand alliances.

Our view that context effects represent an appropriate platform for the study of brand alliances within the B2B domain is also supported by evidence of a 'halo' effect in the form of evaluation transfers from one brand to another (Hutton, 1997). Grounding our study within the broad domain of context effects enables us, (a) to examine the manner in which perceptions related to the quality of a known parent brand (hereto referred as valence) act as a signalling mechanism for the quality of the (unknown) brand alliance, and (b) provides an interpretive frame for the examination of the impact that provision of information has on perceptions towards a brand alliance. Our study offers new insights on the processes involved in managerial evaluation of B2B brand alliances, and adds significantly to the related body of literature. The findings reported here can benefit managerial decision-making in selecting an alliance partner and for promoting the advantages of the alliance.

We present the theoretical underpinnings within which we examine the impact of context effects in Section 2 and develop hypotheses and a research model in Section 3. Section 4 deals with the adopted research design and related methodological activities. The results of the analysis are presented in Section 5. Discussion of the findings and the contributions they make to knowledge, followed by managerial implications and avenues for further research complete this paper.

\section{THEORETICAL UNDERPINNINGS}


Research examining context effects is grounded in theories located in cognitive and social psychology. These theories emphasise the primacy of two cognitive mechanisms of evaluation, namely assimilation and contrast (Zhu \& Meyers-Levy, 2009; Greifeneder \& Bless, 2010). Assimilation occurs when the evaluation of an object or stimulus (usually referred to as target) moves toward the contextual object or stimuli that accompany it (often referred to as context); contrast occurs when evaluation shifts away from the context. Below we present two illustrations of assimilation and contrast.

Stapel, Koomen and Velthuijsen (1998) report that participants evaluated an unfamiliar restaurant more favourably after exposure to a well-known luxury (high valence) rather than a well-known casual (low valence) clothing brand. In this example, the clothing brands serve as the context and the unfamiliar restaurant is the target under evaluation. Assimilation occurred because priming respondents with either a high or a low valence brand resulted in their judgements of an unfamiliar target brand moving towards the context. When the unfamiliar restaurant was primed with a luxury clothing brand, it was judged to be more elegant than when the same restaurant was primed with a casual clothing brand. Herr (1989) finds evidence for both assimilation and contrast. Respondents primed with information about existing car models (either expensive or inexpensive) were asked to evaluate the price of a fictitious car (unfamiliar) and a real car. Unfamiliar cars were appraised as 'less expensive' when primed with an inexpensive car, and 'more expensive' when primed with expensive cars, indicating assimilation. However, when real cars were evaluated this pattern was reversed; priming with expensive cars led to lower evaluations than priming with inexpensive cars, indicating contrast.

According to Levin (2002, p. 147-148) "assimilation and contrast are continuous, co-acting processes rather than all-or-none outcomes and that the net context effect represents the 
balance of these two in any given situation". A number of studies demonstrate that the degree of ambiguity (i.e., the level of information or knowledge) of the target product is an important factor in determining the balance between assimilation and contrast (Meyers-Levy \& Sternthal, 1993; Nam \& Sternthal, 2008; Lee \& Suk, 2010). This perspective underscores two important points, (a) missing information for a target may be inferred from a context (assimilation) simultaneous with shared attributes being compared (contrast), and (b) it is possible to alter the processing of contextual information such that the same context produces assimilation in one situation and contrast in another. Factors found to affect processing include timing of information provision (Jordan \& English, 1989), the descriptive information provided (Fiske, 1998), and the decision maker's expertise (Nam \& Sternthal, 2008).

Two theoretical explanations are proposed to explain when and why assimilation rather than contrast occurs. The first suggests that the extent of feature overlap between a context and a target object determines whether assimilation or contrast is found (Herr, $1986 \&$ 1989). This theory proposes that upon encountering an unfamiliar target object, an individual attempts to categorize it conceptually using a category that is most accessible because of some contextual activation. Accordingly, judgement concerning product attributes of an unknown target brand is made by assigning values similar to those of the known context. Cooke et al. (2002) illustrate how this process leads to assimilation using a hypothetical example of a recommendation of an electronic agent to a potential customer of an unknown or unfamiliar music CD. The authors state that "If the agent recommends the unfamiliar CD with other more familiar titles, the consumer will be better able to make an evaluation. If the familiar CDs are ones that the consumer owns and listens to, he or she may infer that the unfamiliar CD is of similar and may be similar in more tangible dimensions." (Cook et al., 2002, p. 489). Other researchers suggest that the level of cognitive effort people expend in making a 
judgment plays an important role in determining the nature of the resulting context effect (Martin, 1986; Martin, Seta \& Crelia, 1990). Individuals with a high need for cognition display contrast effects while people with a low need for cognition use the less taxing assimilation strategy. Martin et al. (1990) demonstrate the above process in an experiment on the impact of a distraction (thus need for greater cognitive effort) in the form of recitation of random numbers on the formation of impressions.

Despite its frequent application in the consumer domain, only two studies address assimilation and contrast effects in brand alliances. Levin and Levin (2000) examine assimilation and contrast within a dual-branding strategic linkage in which the outcome of the brand alliance (hereto referred as the target brand) is contextualised by the valence of its brand ally and provision of information. They find assimilation effects to be stronger when, (a) the target brand is presented in an ambiguous rather than detailed manner, (b) the two brands are presented jointly as part of an alliance, and (c) the brand ally is positively perceived. These results are confirmed in a subsequent study by Levin (2002).

In conclusion, the review of the literature confirms that assimilation and contrast effects are well established phenomena in social psychology and represent a suitable platform for the study of context effects in brand alliances; nonetheless, related extant research is exclusively located within the B2C domain. The impact of context effects on evaluations of brand alliances in the B2B domain represents the main purpose of this study. We adopt product feature overlap as theoretical explanation based on the following rationale. The organisational buying behaviour literature offers evidence that, due to high levels of associated risk, evaluations of new products or services are complex tasks that demand considerable expertise and formality (Spekman \& Stern, 1979; Henthorne, LaTour \& Williams, 1993). We infer that related decisions necessitate considerable cognitive effort by 
the participants. Brand alliances represent new offerings and consequently evaluations involve high levels of cognitive effort. It is therefore logical to conclude that the relatively uniform cognitive effort required in evaluating B2B brand alliance represents an analytical limitation. On the other hand, the idiosyncratic nature of brand alliances implies considerable variation in terms of feature overlap between B2B brand alliances and consequently represents an appropriate theoretical platform for the study of B2B brand alliances.

\section{CONCEPTUAL FRAMEWORK AND RESEARCH MODEL}

Figure 1 presents the conceptual framework upon which we develop specific research hypotheses. Debate in the preceding section establishes the link between contextual factors and assimilation and contrast effects. Levin and Levin (2000) and Levin (2002) suggest that contextual factors determine not only the direction (assimilation or contrast) but also the magnitude of evaluations of a brand alliance (they use the term 'inferred value or imputation'). However, the impact of contextual factors on the evaluations of a brand alliance is contingent on whether assimilation or contrast is the dominant cognitive mechanism. For example, from signalling theory (in Section 3.2 below) we expect that perceptions of a known brand ally are transferred to the brand alliance. However, the resulting transfer effects depend on whether assimilation or contrast is the dominant mechanism. If the known brand ally is associated with positive perceptions, under assimilation the transfer will be positive (perceptions of the brand alliance move towards those of the brand ally) while under contrast we expect that perceptions of the brand alliance will be negative (perceptions move away from the brand ally).

Insert Figure 1 Here 
The research model is presented in Figure 2. Based on the debate in Ziamou and Ratneshwar (2003), Nam and Sternthal (2008), along with evidence presented by Martin et al. (1990), Stapel et al. (1998), Levin and Levin (2000), and Cooke et al. (2002), we examine the effects of two contextual factors, (a) valence of the known brand ally and, (b) amount of information provided for the target brand/product or service resulting from the brand alliance. The relevance of valence, in the form of quality of past experiences with brand alliances, is confirmed by Gammoh and Voss (2013) while the influence of information in B2B branding is established by Lynch and de Chernatony (2007) and Brown et al. (2011). We argue that, unlike current research that focuses on overall evaluation, the stability of the research hypotheses across salient attributes merits attention. Such approach acknowledges differential behaviour of attributes, and is in accord with the core concept of feature overlap on which the related theory is developed. We present and discuss our research hypotheses below.

\section{Insert Figure 2 Here}

\subsection{Establishing Assimilation or Contrast}

Consistent with above logic the first step involves establishing whether assimilation or contrast is the dominant cognitive mechanism when evaluating B2B brand alliances. We expect that when customers encounter an unknown product (the result of a brand alliance) evaluations are based on their pre-existing perceptions (valence) of the features or attributes of the known brand partner or ally; consequently transfer effects are present and assimilation is evident (Herr, 1986 \& 1989). This is consistent with Levin and Levin (2000, p. 44) who state that "the strategic linkage of two brands promotes the expectancy of similarity of qualities", and with results by Nam and Sternthal (2008) that indicate dominance of 
assimilation amongst experts. We accept evidence by Martin et al. (1990) and Levin and Levin (2000) that assimilation is especially evident when the known brand ally has positive rather than negative valence, leading to our first hypothesis.

$\mathrm{H}_{1}$ : When the known brand ally has positive rather than negative valence, assimilation will be evident.

In addition, we propose that for the $\mathrm{B} 2 \mathrm{~B}$ domain there is a need to re-evaluate the claim by Stapel et al. (1998), Levin and Levin (2000), Cooke et al. (2002), and Lee and Suk (2010) that ambiguous rather than detailed information leads to greater assimilation. Our argument is based on the rationale that compared to consumer markets, managerial decisions in $\mathrm{B} 2 \mathrm{~B}$ are characterised by greater product and service complexities due to the importance of technical factors (Wilson, 2000; Wilson \& Woodside, 2001), and that "managers generally collect information to reduce decision making uncertainty. Hence, a lower amount of counter intuitiveness and greater consistency with anticipations are viewed favorably (in terms of affecting information utilization)" (Deshpande \& Zaltman, 1987, p. 117). Collectively the above lead us to suggest that within the B2B domain assimilation prevails when the provision of information about the brand alliance is detailed (we use the term well-specified as in Levin \& Levin, 2000) rather than ambiguous. Therefore we propose,

$\mathrm{H}_{2}$ : When the target brand is well-specified rather than ambiguous, assimilation will be evident.

\subsection{Evaluation of a Brand Alliance}

We proceed to develop hypotheses related to evaluations of a brand alliance on the premise that $\mathrm{H}_{1}$ and 2 are supported (see earlier explanation of the contingent or moderating impact of 
associated cognitive mechanisms). Herr, Sherman and Fazio (1983) suggest that evaluative judgements of unknown or ambiguous stimuli are performed by reference to a standard. Within the brand alliance literature the signalting and information integration theories demonstrate that the known brand ally acts as such a standard. According to Rao et al. (1999, p. 259) "A signal is an action that the seller can take to convey information credibly about unobservable product quality to the buyer." (italics in original). Within the brand alliance domain Rao and Ruekert (1994, p. 89) state that "If one brand name on a product gives a certain signal of quality, then the presence of a second brand name on the product should result in a signal that is at least as powerful, if not more powerful than, the signal in the case of the single brand name." The above imply that, given customers' lack of information, the reputation of a known brand acts as a signal of the unobservable qualities of the product or service resulting from a brand alliance. Application of the signalling theory in brand alliances research is found in, amongst others, Simonin and Ruth (1998), Fang and Mishra (2002), Washburn, Till and Priluck (2004), Voss, Gammoh and Chakraborty (2006) and Voss, Gammoh and Fang (2012).

Information integration theory refers to the processes involved in the formation and/or modification of existing attitudes, beliefs, opinions or evaluations as a result of integrating additional information received from different sources (Anderson, 1981). In other words, consumers integrate new information within existing structures of beliefs, attitudes and evaluations. It therefore follows that evaluations of a brand alliance are integrated or are based on pre-existing evaluations of the brand allies. A number of studies, such as Simonin and Ruth (1998), Baumgarth (2004), Lafferty, Goldsmith and Hult (2004), Lafferty and Goldsmith (2005), Bluemelhuber, Carter and Lambe (2007) and Olsen and Lanseng (2012) support the relevance of information integration theory in the study of brand alliances. 
The transfer of valence (i.e., quality) signals from the brand allies to the product or service resulting from their collaboration suggested by signalling theory provides the basis on which information is integrated during the evaluation process. Based on the above theoretical foundations in signalling and information integration theories, we hypothesize that:

$\mathrm{H}_{3}$ : In the presence of a positively rather than a negatively perceived known brand ally evaluations of a brand alliance will be higher.

Expanding earlier debate related to $\mathrm{H}_{2}$ we find considerable evidence linking systematic collection and processing of information with organizational decision making (see for example Spekman \& Gronhaug, 1986; Kohli, 1989; Park \& Bunn, 2003; Woodside, 2003; Bendixen, Bukasa \& Abratt, 2004; Souchon et al., 2004). Bunn (1994) places search for information at the core of organizational buying, and Gilliland and Johnson (1997) consider that extensive engagement and active processing of information by business managers lead to a positive relationship between greater search and use of information, and attitudes towards a brand. In addition there is evidence that provision of information is related with perceptions of risk involved in industrial buying behavior. For example Brown et al. (2011, p. 194) state that "established organizational buying models ... suggest that buyers offset heightened levels of risk by pursuing disciplined purchasing strategies built upon an extensive information search process." The role of information search in organizational buying behaviour is also evident in the rationale underpinning the buyclass model proposed by Robinson, Faris and Wind (1967). We therefore conclude that provision of information in B2B brand alliances plays a critical role in their evaluations, and assuming positive provision of information, we propose that:

$\mathrm{H}_{4}$ : When the target brand is well-specified rather than ambiguous, evaluations of a brand alliance will be higher. 
In hypothesis $\mathrm{H}_{4}$ we argue for a positive relationship between target brand well-specified (i.e., provision of detailed information) and evaluation of a brand alliance. Given that the impact of valence on cognitive processes, and specifically on information processing, is welldocumented (e.g., Tiedens \& Linton, 2001; Delplanque et al., 2004; Chartrand, van Baaren \& Bargh, 2006) we expect evidence of interaction effects between valence and provision of information. We consequently predict that the positive relationship between target brand well-specified and evaluation is stronger when a brand ally has positive valence. The proposed asymmetric contribution of valence and information provision on brand alliance evaluation follows from research indicating a positive relationship between attitudinal congruency and use of information (e.g., Walker, Vogl \& Thompson, 1997; Meffert et al., 2006). Managers with positive perceptions of a brand ally will attempt to reinforce or confirm their perceptions through collection and analysis of information, while those with negative perceptions are unlikely to engage in considerable information processing. The above rationale leads us to the following expression of interaction effects between provision of information and valence.

$\mathrm{H}_{5}$ : A positively perceived known brand ally and well-specified information for the target brand will result in highest evaluations of a brand alliance.

\section{METHOD}

\subsection{Stimuli Development and Measures}

The first task was to identify an appropriate real brand to act as the known brand ally. In order to test the hypotheses the selected brand should exhibit both positive and negative valence. Feedback from a panel of five experts (see composition of industry experts in the 
Appendix) suggested that SAP, a well-known computer software company used by businesses, is a suitable known brand ally on the grounds that, a) it represents a non-trivial investment to a business and therefore related decisions require substantial cognitive engagement, b) it is not sector specific, and c) respondents are likely to have positive or negative views of the brand, irrespective of whether or not used by their companies.

The second task was specification of the target brand. We employ a fictitious rather than a real brand, a decision that is in line with studies located in the assimilation and contrast domain (see for example Herr, 1989; Herr, Sherman \& Fazio, 1983; Meyers-Levy \& Sternthal, 1993; Stapel et al., 1998; Levin, 2002; Lee \& Suk, 2010). In addition, accepting that a brand alliance is a special form of brand management and specifically of a brand extension (Helmig, Huber \& Leeflang, 2008), we refer to brand extension literature that employs fictitious brands (see, for example, de Ruyter \& Wetzels, 2000; Swaminathan, Fox \& Reddy, 2001; Mao \& Krishnan, 2006; Nan, 2006).

A multifunctional photocopier (MFP) is considered a suitable product match for a business software company. The new product resulting from the alliance combines standard copying and printing facilities with the ability to interface with integrated business software; information placed on the photocopier could be directly transmitted to management systems, and in turn reports and personalised communications could be generated. Feedback from the expert panel suggested this product is commercially desirable and technically viable. This view is corroborated by recent market announcements about a new generation of MFPs. We name this new product resulting from the brand alliance between SAP and Calvé as Calvé Varioprint 3622, hitherto referred as the target brand.

Using feedback from the same experts, the known brand ally (SAP) is evaluated in terms of quality, reliability, performance and ease of use; an overall opinion measure is also included 
for determining valence. For the target brand, content analysis of advertisements for MFPs identified the following attributes as relevant benefits to be used as evaluation criteria: reliability, print quality, speed of printing, paper capacity and ease of use. Each of the above is measured using single item questions on an 11-point rating scale anchored at very poor $(0)$ and excellent (100).

\subsection{Study Design}

Consistent with other studies on assimilation and contrast, we employ a between-subjects experimental design (in the form of advertisements) with valence of the known brand ally and target brand information as the two experimental conditions. Valence of the known brand ally, tested at two levels, is not controlled for at the experimental stage; respondents are classified post hoc as having either a positive or negative perception of the known brand ally based on their answers to the related overall opinion question (in this respect it is a quasiexperimental design). Information is also tested at two levels: target brand well-specified, and target brand ambiguous. In the information well-specified condition the advertisements contain detailed specifications of functionality while in the ambiguous condition the advertisements contain little information about the target brand/product.

We employ a two-stage approach. In stage one we control only provision of information and the resulting evaluations provide benchmarks when testing for assimilation and contrast. Two advertisements are created which depict only the target brand (i.e., no reference is made to the known brand ally). One advertisement contains detailed information (target welldefined) while the other offers little information (target ambiguous) about the target brand (see Appendix). A common opening page is used which explains to the participants that the study seeks their views about a new product currently under development. Evaluations, on 
the above specified attributes, following exposure to these advertisements are labelled as "pre-alliance".

In stage two we augment the two advertisements from stage one by including the known brand ally. The opening page explains the proposed collaboration between SAP and Calvé and provides a short description of the two brands. Respondents are then exposed to an advertisement of the known brand ally and are requested to indicate their judgment on the attributes indicated in the previous section. An advertisement (well-specified or ambiguous) follows that depicts both the known brand ally and the target brand, and evaluation questions of the target brand complete the task. We label these evaluations as "post-alliance".

\subsection{Sampling and Data Collection}

The population comprised a cross section of large (> 250 employees) UK-based companies operating in the $\mathrm{B} 2 \mathrm{~B}$ domain. This choice was based on the expectation that managers from larger companies are more likely to be familiar with the known brand ally and engage in activities similar to those in the planned brand alliance. An appropriate sampling frame was obtained from a specialist list broker. The list contained detailed company information as well as contact details of a senior decision maker to whom the survey was addressed. Each of the experimental scenarios was randomly allocated across 1250 potential respondents and the data were collected through a postal self-completion survey, using guidelines outlined in Dillman (2007). After excluding incompletes and undeliverables, 402 usable replies were received, giving an overall response rate of $32 \%$. Table 1 indicates that minimum analytical requirements are met and the sample characteristics in Table 2 denote broad comparability between the experimental conditions. Non-significant differences in replies obtained from early and late respondents confirms lack of non-response bias (Armstrong \& Overton, 1977). 


\section{$5 \quad$ ANALYSIS AND RESULTS}

\subsection{Information Manipulation Checks and Establishing Valence}

Before testing the hypotheses we test the efficacy of the experimental treatments of information and classify respondents as having either positive or negative valence towards the known brand ally. In terms of manipulation of information, independent samples t-tests, from the target-only conditions, indicate significant differences for all attributes except print quality (see Table 3).

\section{Insert Table 3 Here}

In line with expectations that SAP would be viewed positively by some respondents and negatively by others, subjects' perceptions followed a bimodal distribution and the scale midpoint represents an appropriate value for classification (see histogram in the Appendix). Consequently, we treat values above 50 as representing positive valence for the known brand ally and those equal to or below 50 as negative valence. This is in line with previous research in assimilation and contrast (Levin \& Levin, 2000; Nam \& Sternthal, 2008).

\subsection{Testing for Assimilation and Contrast}

Hypotheses 1 and 2 predict that assimilation will be more evident when the known brand ally has positive valence and when detailed information is provided for the outcome of the brand alliance. To test these hypotheses one sample t-tests, using the corresponding mean values from Table 3 as test values, are applied and the results are presented in Table 4. 


\section{Insert Table 4 Here}

Before discussing the results we set out our logic of interpretation. Overall, the mean values of the attributes of the known brand ally associated with respondents with positive valence (upper part of column 2) are higher than the pre-alliance mean attribute values of the target brand for both types of presentation (upper part of columns 4 - target well-specified, and 7 target ambiguous). If the post-alliance evaluation of a specific attribute of the target brand (upper part of columns 5 and 8) demonstrates a significant increase to the corresponding prealliance value, assimilation takes place. The presence of the known brand ally in the brand alliance (i.e., post-alliance) results in a significant increase (movement towards the known brand ally) compared to when no known brand ally was present (i.e., pre-alliance). A change in mean values in the opposite direction, i.e. significant decline from pre-to-post-alliance (movement away from the known brand ally) denotes contrast. To aid interpretation, we provide an example using the results for the reliability attribute of the target brand with a positive valence context and with the target brand well-specified. The pre-alliance mean value (i.e., when the target brand was presented without reference to the known brand ally) was 60.00 . When the same brand was presented as a brand alliance with the known brand ally (post-alliance) we observe a significant increase in the mean value to 69.02, which demonstrates assimilation.

Applying the same logic to the information in Table 4 confirms presence of transfer effects in the form of assimilation (change in all significant tests is towards the context effect). Supporting $\mathrm{H}_{1}$, assimilation is more evident when the valence of the known brand ally is positive rather than negative. For positive valence of the known brand ally, irrespective of whether the target brand is well-specified or ambiguous, there is significant positive change between pre- and post-brand alliance values for all attributes except paper capacity in target 
ambiguous ( 9 of 10). For negative valence of the known brand ally, the results provide evidence of assimilation for four of the five attributes (i.e., reliability, speed, capacity and ease of use) for the target well-specified condition (4 of 10). The claim in $\mathrm{H}_{2}$, that assimilation is more evident when detailed information ( 9 of 10) rather than ambiguous ( 4 of 10) about the target brand is provided, is also supported. Further insight is gained by focusing on the pattern of results. Specifically, we observe lack of effects only when the known brand ally has negative valence and the target brand is presented in an ambiguous manner. Collectively the above observations provide evidence of context effects in the evaluation of brand alliances.

\subsection{Evaluation of a Brand Alliance}

Hypotheses 3 to 5 relate to evaluations of the brand alliance under different conditions of valence and information. Higher evaluations are hypothesised, (a) under positive rather than negative valence of the known brand ally $-\mathrm{H}_{3}$, (b) when the target brand is well-specified rather than ambiguous $-\mathrm{H}_{4}$, and (c) positive valence of the known brand ally and target brand well-specified result in the highest level of evaluation $-\mathrm{H}_{5}$. To test the above hypotheses the data are subjected to MANOVA with valence and information as fixed factors. Using Roy's largest root, we find significance for the main effects for valence $(\theta=0.365, \mathrm{~F}(5,251)=$ 18.30, Sig. $=.000)$, information $(\theta=0.280, F(5,251)=14.06$, Sig. $=.000)$ and their interactions $(\theta=0.118, F(5,251)=5.91$, Sig. $=.000)$; thus we offer support for all the above hypotheses.

\section{Insert Table 5 Here}

Having established the significance of valence and information at the multivariate level we focus on their impact on specific evaluation attributes. The information in Table 5 shows that 
the main effects of valence are significant across all attributes and the mean values of the evaluations are in line with $\mathrm{H}_{3}$ (positive greater than negative). The main effects of information are significant for speed of printing and paper capacity and the corresponding mean values are consistent with expectations in $\mathrm{H}_{4}$ (well-specified greater than ambiguous). Interactions are significant only for paper capacity. In line with $\mathrm{H}_{5}$, Figure 3 shows that for target ambiguous there is little difference in evaluations related to positive and negative valence; however for target well-specified evaluations are substantially higher especially for positive rather than negative valence.

Insert Figure 3 Here

\section{DISCUSSION AND CONCLUSIONS}

Our study aims to advance understanding of the role that context effects have on evaluations of brand alliances within the B2B domain. Assimilation and contrast are the underpinning analytical mechanisms with feature overlap providing the study's theoretical lens. Using an experimental design we test for evidence of assimilation and contrast across product evaluation attributes and examine the main and interaction effects of positive and negative valence towards the known brand ally (the known brand partner) and information provided for the target brand (product or service as a result of a brand alliance) on evaluations of a brand alliance.

Our results indicate that assimilation prevails in evaluations of B2B brand alliances across all attributes under examination. This finding is in line with predictions grounded in transfer effects. We observe transference of evaluations from the known brand ally to the unknown brand alliance, a phenomenon consistent with theories of signalling, information integration 
(Rao and Ruekert, 1994; Gammoh, Voss \& Chakraborty, 2006) and brand equity (Keller \& Aaker, 1992; Washburn et al., 2004). Contextual cues, in the form of valence and provision of information, act as qualifiers to the above conclusions. Our analysis confirms the prediction that assimilation is more evident when the known brand ally has positive valence $\left(\mathrm{H}_{1}\right)$. This outcome is consistent with results from the B2C domain reported by Martin et al. (1990) and Levin and Levin (2000). We find support for our expectation that assimilation is more evident when detailed (target well-specified) rather than ambiguous information about the brand alliance is presented $\left(\mathrm{H}_{2}\right)$.

Lack of contrast effects is of relevance to the subject matter, especially since Herr et al. (1983) and Levin and Levin (2000) report evidence of contrast when detailed information (i.e., target well-specified) about the target is provided. A possible explanation is contained in studies by Nam and Sternthal (2008), and Stewart and Malaga (2009) who report differential behaviour between experts and novices. Specifically, we posit that business managers possess greater knowledge and experience with the target product than the average consumer (i.e., they are experts). In judging the target brand, they access knowledge about the product category and use benefits inferred from the context to interpret the target and thus exhibit assimilation. Therefore, irrespective of the amount of target brand information provided, business managers use contextual information to complement their internal knowledge of the target category. No comparison (contrast) process between target and context is triggered by the availability of more target brand knowledge. This outcome is consistent with the two-process view that assimilation occurs during interpretation when accessible and applicable contextual information is used to interpret a target (Nam and Sternthal, 2008). Moreover, when the well-known brand ally has positive valence there is evidence of assimilation irrespective of information, while, when the valence is negative, assimilation is evident only when detailed information about the brand alliance is provided 
(implied interaction effects). These observations accord with Levin (2002), whose study emphasises the centrality of selecting a reputable partner before considering other aspects (e.g., promotion) of the brand alliance.

The results indicate that contextual factors have a significant impact on evaluations of the brand alliance. However, we observe differential behaviour in terms of both the two contextual factors and the evaluation attributes. Guided by Levin and Levin (2000) and Stapel et al. (1998) we predict, and the result confirm that, for all attributes, brand alliances which include a known brand ally with positive valence result in higher evaluations $\left(\mathrm{H}_{3}\right)$. Considered in conjunction with earlier results these findings amplify the importance of partner selection. We offer partial support for $\mathrm{H}_{4}$, i.e. the main effects of information are significant for two of the five attributes (speed of printing and paper capacity) and in both cases the direction of evaluation is in line with expectations (i.e., detailed rather than ambiguous information results in higher evaluations). Limited evidence of interaction effects $\left(\mathrm{H}_{5}\right)$ between valence and information indicates independence of these two contextual factors.

\section{CONTRIBUTIONS, MANAGERIAL IMPLICATIONS AND FURTHER}

\section{RESEARCH}

This paper investigates the impact of context effects on perceptions of B2B brand alliances. It addresses the scarcity of studies examining assimilation and contrast within brand alliances and pioneers the study of related issues in the $\mathrm{B} 2 \mathrm{~B}$ domain at the individual attribute rather than overall brand alliance evaluation level. The theoretical foundations of our study are located in the $\mathrm{B} 2 \mathrm{C}$ literature. A number of authors question whether the $\mathrm{B} 2 \mathrm{~B}$ and $\mathrm{B} 2 \mathrm{C}$ domains are dichotomous, with most suggesting a blurring of lines between the two (e.g., 
Fern \& Brown, 1984; Wilson, 2000; Wind, 2006; Gummesson \& Polese, 2009). These authors view greater integration of the two streams to be the result of modern business and call for research to focus on commonalities to identify generalizable propositions across business and consumer marketing.

This study is a response to the above and it is consistent with the orientation adopted by some of the most influential (see review by Herbst et al., 2012) investigations in B2B branding (see for example Mudambi, Doyle \& Wong, 1997; Mitchell, King \& Reast, 2001; Mudambi, 2002; Bendixen, Bukasa \& Abratt, 2004) and papers published in the 2011 special issue of IMM on B2B branding. In response to the call for generalizable research our study offers insight into the ongoing debate regarding convergence and divergence between $\mathrm{B} 2 \mathrm{~B}$ and $\mathrm{B} 2 \mathrm{C}$ marketing. The findings lead to a number of contributions to theory and practice as discussed below.

\subsection{Contributions to Theory}

Consumer studies demonstrate transfer effects between allied brands. In terms of valence, the accepted view is summarised by Levin and Levin (2000, p. 45) who state that "Consumers may assume that a high-quality product will ally itself only with other highquality products because they know that managers will be motivated to avoid damaging their product's reputation by a poor alliance." Levin and Levin (2000) qualify their views of transfer effects by considering how availability of attributes influences perceptions of brand alliances. They suggest that when the brand ally and the context brand share common attributes, contrast to the known brand ally results. Alternatively, when evaluating attributes unique to the brand alliance, the result is neither assimilation nor contrast. Compared to extant studies based on overall evaluations of a brand alliance, our disaggregate attribute 
approach enables testing the above claim in the B2B domain. For the two 'shared' attributes - reliability and ease of use - we observe assimilation rather than contrast. Assimilation is also evident in the case of the attributes unique to the brand alliance, namely, print quality, speed of printing, and paper capacity. Consequently, our results in B2B diverge from the views expressed by Levin and Levin (2000) regarding availability of attributes.

For provision of information, the prevailing view in consumer research is that "A target that is ambiguous lends itself to similarity testing because of flexibility in how it can be interpreted, and an assimilation effect results. Dissimilarity testing is proposed to be more likely when the target is unambiguous, resulting in a contrast effect." (Lee \& Suk, 2010, p. 896). Drawing on organizational buying behavior literature we argue that the above prediction does not extend to the $\mathrm{B} 2 \mathrm{~B}$ domain. Our results suggest a mixed picture. As expected, detailed information leads to assimilation irrespective of the valence of the known ally. However, as prescribed by B2C literature, we find assimilation when the information about the brand alliance is ambiguous and the known brand ally has positive valence. Therefore, we suggest that assimilation is not only contingent on the specific research domain but also on the pattern of interactions between valence of known ally and provision of information about the brand alliance. Further elaboration on provision of information is provided by Stapel et al. (1998) who conclude that information about abstract product attributes leads to assimilation while information about concrete product attributes results in contrast. The uniformity of pattern of our findings with assimilation evident irrespective of level of attribute abstraction raises questions regarding the transferability of this claim to the B2B domain.

In terms of evaluations, the expectation that brand alliances which include a known ally with positive valence achieve higher evaluations is supported. Our results confirm those reported 
in Levin and Levin (200) and indicate convergence in the behaviour of signalling and information processing theories in the $\mathrm{B} 2 \mathrm{C}$ and $\mathrm{B} 2 \mathrm{~B}$ domains. Through attribute level analysis, we extend knowledge by demonstrating stability of the predictions derived from these theories across different attributes of a brand alliance. Support for our claim that detailed rather than ambiguous information of the brand alliance leads to higher evaluations is contrary to results reported in studies located in the B2C literature (see for example Levin \& Levin, 2000; Cooke et al., 2002; Lee \& Suk, 2010) and supports our logic presented in the research hypotheses section of this paper. In the absence of reference points due to lack of related literature, we speculate that the observed patterns reflect relative degrees of attribute 'tangibility' or 'concreteness'. Provision of information impacts on evaluations of attributes that can be independently assessed (speed of printing and paper capacity) while it has no effect on evaluations of attributes that require personal experience (reliability, print quality and ease of use). The technical nature of most products in the B2B domain and multiple individuals involved in the decision process offer a possible explanation (Brown, Bellenger \& Johnston, 2007). We view these results to indicate that provision of detailed information acts as legitimisation of the brand alliance in the eyes of decision makers. Analysis at attribute level enables us to clarify the above finding. In particular we offer evidence of differential impact of information on the evaluation criteria and suggest that the degree of attribute concreteness is the factor that determines the effectiveness of information provision. Collectively, we conclude that although the B2C literature on assimilation and contrast effects provides insights into B2B brand alliances and their evaluations, the expected patterns are not always as predicted. We attribute this difference to two factors, a) the greater product knowledge and technical expertise possessed by managers as compared to consumers, and b) the greater formality and risk associated with purchasing decisions in the B2B domain. 
Consequently, we suggest caution and consideration of the important differentiating elements of the two domains.

\subsection{Managerial Implications}

Entering into collaborative activities such as brand alliances involves a certain degree of uncertainty. The results presented here offer guidance, thus minimization of risk, for the management of B2B brand alliances in terms of partner selection and transmission of information to the target audience. At a broad level we find conclusive evidence that the involvement of a known brand results in transference of perceptions of its quality (being positive or negative) to the outcome of a brand alliance (i.e., assimilation). These results have important implications regarding selection of a brand ally, and indicate that a brand alliance can benefit by leveraging the participation of a reputable known ally. Although the logical conclusion is that, in selecting an ally, only those brands with positive valence should be considered, we envisage cases where the valence of the known brand ally will not be positive due to, for example, use of a controversial production practice. In such cases managers can ameliorate the detrimental effects of assimilation because of negative valence by abating the amount of information provided for the brand alliance.

The above offer an overarching explanatory framework, however from a managerial perspective the interest is on the drivers that lead to (higher) evaluations. Although the primacy of selecting a positively perceived known brand is confirmed for all attributes of the brand alliance, we acknowledge problems with a priori classification of potential customers. Market intelligence is a solution, however commercialization through existing customers of the known brand ally is a potentially less risky and financially less demanding alternative. This view is based on the premise that customer loyalty is, at least to a degree, a 
demonstration of positive quality perceptions about a supplier. Accepting this premise means that commercialization of a brand alliance through such customers will result in targeting those with positive valence toward the know brand ally. However, following B2C literature, we suggest that, to avoid alienation of loyal customers, issues of between-partner congruity as well as brand and product fit need to be carefully considered (see for example Simonin \& Ruth, 1998; Walchli, 2007).

Furthermore, our results demonstrate that information provision is an important determinant of evaluations of a brand alliance. However, unlike valence of the known brand ally, provision of information is significant only for tangible attributes, i.e. attributes that can be evaluated without in-use experience (e.g., speed of printing). These results lead to the following recommendations, (a) quality-related messages about an alliance's attributes that are difficult to be independently evaluated should be avoided because they have no impact on the formation of perceptions, and such messages could potentially blur the information about tangible attributes, (b) detailed information, involving results from independently conducted tests that benchmark the tangible attributes of the outcome of the brand alliance against other comparable offerings, would be more credible, and (c) the message should be communicated through multiple channels in order to reach all parties involved in the purchase decision making process.

\subsection{Study Limitations and Suggestions for Further Research}

Our findings are contingent on the following limitations which we identify as potential areas for further research. Future studies should include both purchase and buyer characteristics, along with aspects of the buying process present in $\mathrm{B} 2 \mathrm{~B}$ organizations. Other factors that could be included in further research are - relative importance of the evaluation criteria, 
perceptions of risk involved in the purchase, relative price of the brand alliance product, and relationship variables with the brand allies. The moderating impact of market and organizational factors should be examined. The results need to be confirmed for other forms of brand alliances, such as product bundling or ingredient branding, and for other product categories (for instance, alliances between services and products and within services). Unlike the present study that focuses on the effects due to one known brand partner, future research should include effects resulting from both partners such as between-partner congruity, product fit, brand fit and attitudes, which are widely applied variables in the domain of $\mathrm{B} 2 \mathrm{C}$ brand alliance evaluations.

The external validity of the results needs to be established through examinations based on real advertisements placed in publications read by the target audience. Use of multi-items scales (compared to single questions employed in this study) in evaluating the context and target brands could improve sensitivity and content validity. Investigation of the behavior of different types of attributes in different sectors could help understand whether the degree of assimilation is contingent upon degree and nature of feature overlap and type of sector. We also suggest further research on the differential behavior of experts and novices. Despite the stated limitations, this study sheds light into the behaviour of assimilation and contrast and the impact of context effects in B2B brand alliances. We provide suggestions for how researchers may take this research further, and how managers might respond in the light of understanding of customers' evaluation of products or services resulting from B2B brand alliances. 


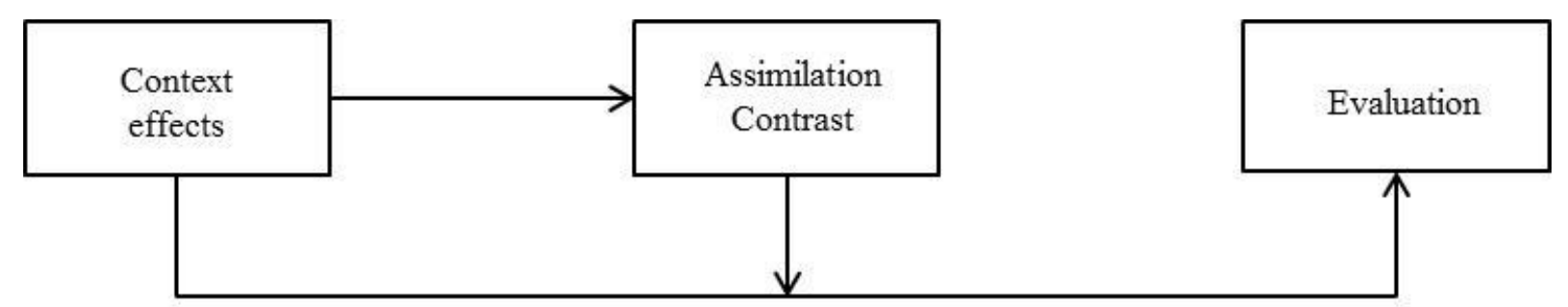

Figure 1: Conceptual Framework 


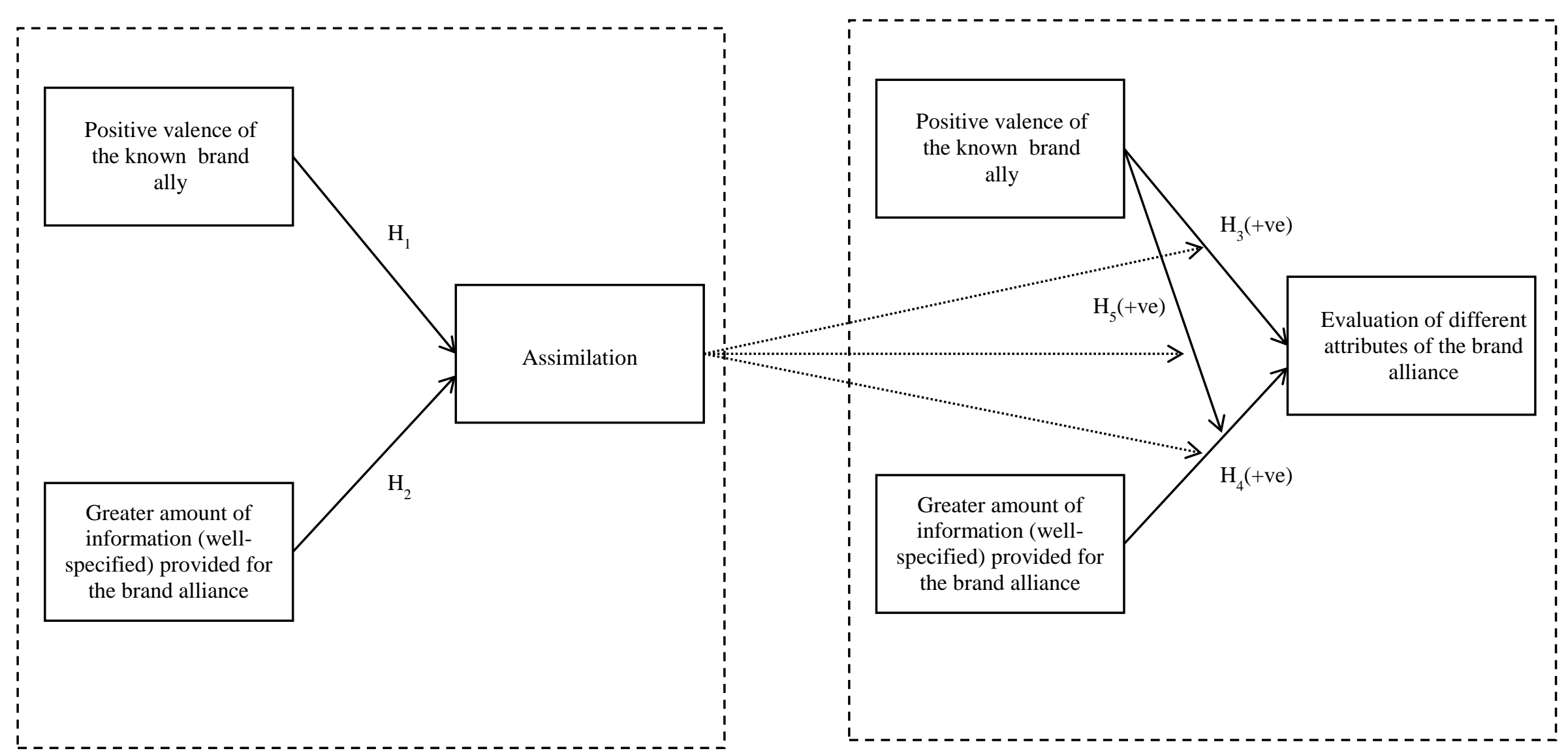

Figure 2: Testing the impact of valence and information on evaluation of brand alliance attributes 


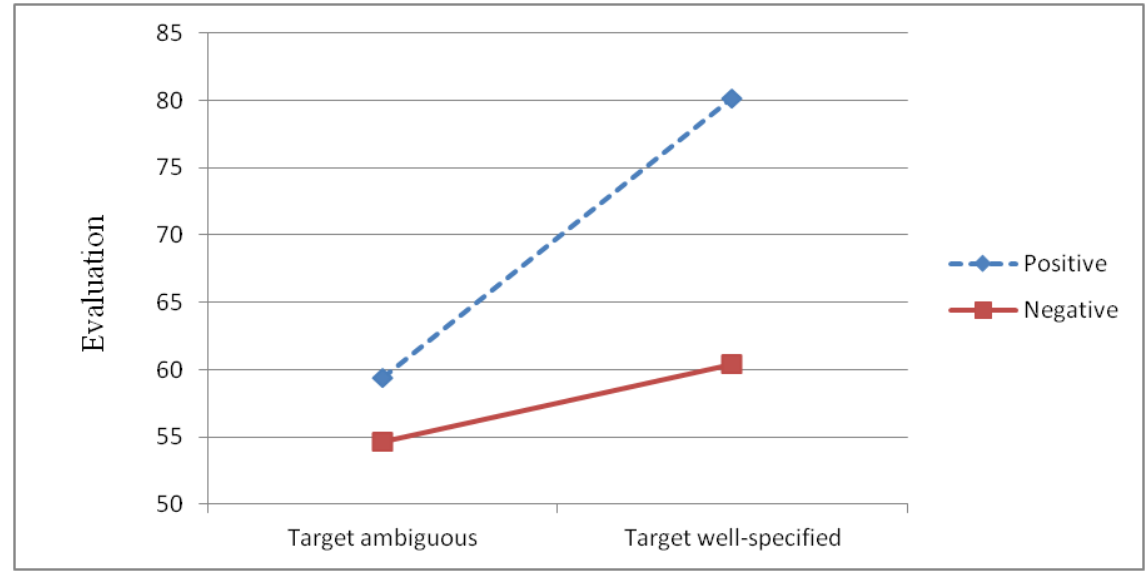

Figure 3: Magnitude of evaluations for paper capacity - Interactions 
Table 1: Response pattern

\begin{tabular}{|lcccc|}
\hline Context & $\begin{array}{c}\text { Valence of } \\
\text { known brand } \\
\text { ally }\end{array}$ & $\begin{array}{c}\text { Target well- } \\
\text { specified }\end{array}$ & $\begin{array}{c}\text { Target } \\
\text { ambiguous }\end{array}$ & Total \\
\hline Pre-alliance & $\mathrm{n} / \mathrm{a}$ & 62 & 76 & 138 \\
Brand alliance & Positive & 51 & 63 & 114 \\
& Negative & 69 & 81 & 150 \\
Total & 182 & 220 & 402 \\
\hline
\end{tabular}

Note: For a medium effect size and power of 0.80 with a level of significance of 0.05 , the required total sample size is 128 (using GPower 3.0 software). This results in 21 observations per experimental condition, which is lower than all cell sizes.

Near equivalence in the number of replies for the experimental conditions offers support for the adopted analytical approach and use of Type III sums of squares eliminates residual problems due to slight differences in frequencies (Mendes, 2007). 
Table 2: Sample characteristics

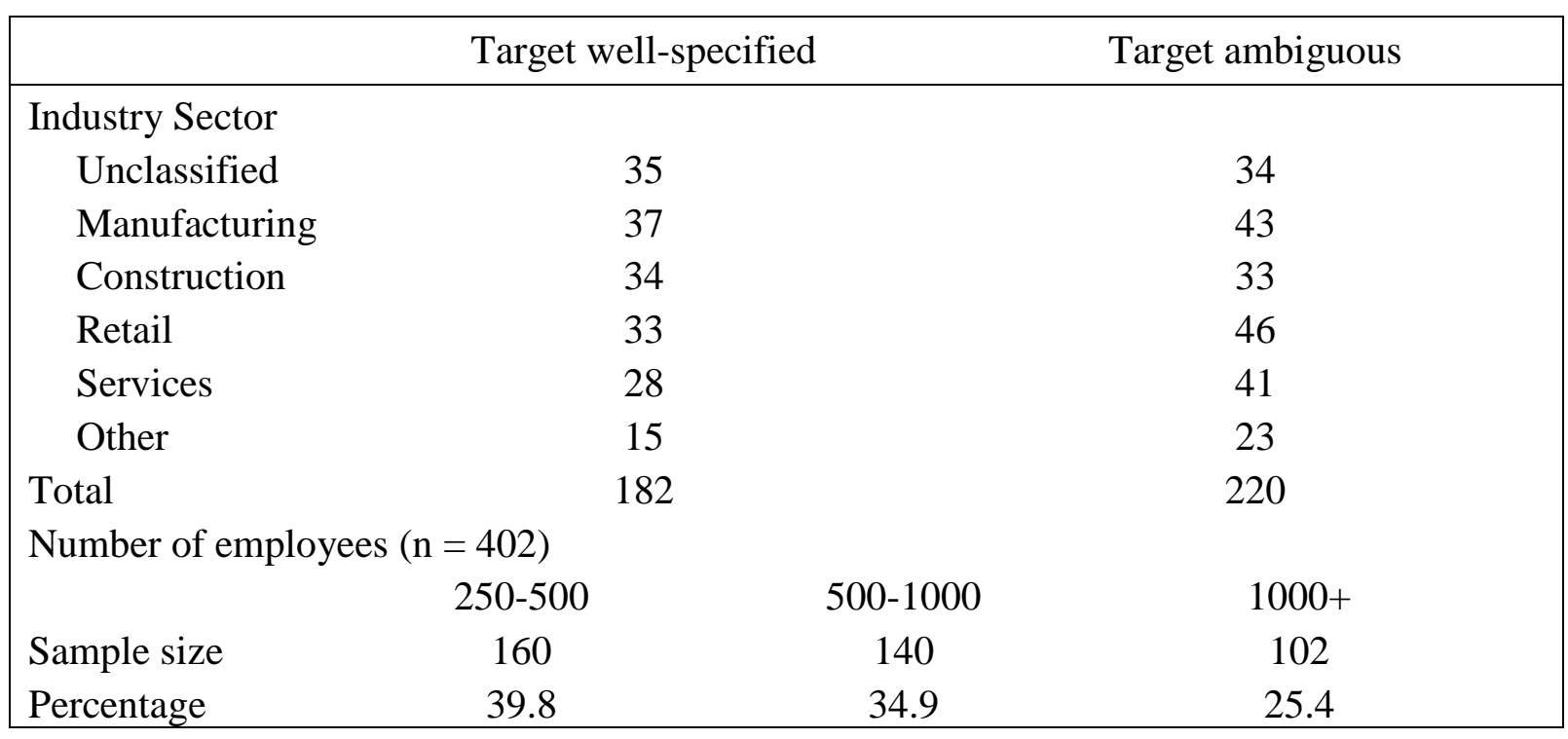


Table 3: Mean evaluations of target brand by information

\begin{tabular}{|lccc|}
\hline Evaluation criteria & $\begin{array}{c}\text { Target well-specified } \\
(\mathrm{n}=182)\end{array}$ & $\begin{array}{c}\text { Target ambiguous } \\
(\mathrm{n}=220)\end{array}$ & t-values \\
\hline Reliability & 60.00 & 54.40 & $2.12^{*}$ \\
Print quality & 59.05 & 56.00 & $1.27^{\mathrm{ns}}$ \\
Speed of printing & 67.62 & 56.40 & $3.77^{* *}$ \\
Capacity & 70.95 & 56.80 & $4.47^{* *}$ \\
Ease of use & 64.76 & 52.00 & $3.83^{* *}$ \\
\hline
\end{tabular}

Note: $* p<0.05 ; * * p<0.001$; ns $=$ not significant 
Table 4: Testing for assimilation and contrast

\begin{tabular}{|c|c|c|c|c|c|c|c|c|}
\hline \multirow[b]{2}{*}{$\begin{array}{l}\text { Attributes of } \\
\text { known brand } \\
\text { ally (SAP) }\end{array}$} & \multirow[b]{2}{*}{$\begin{array}{c}\text { Mean } \\
\text { evaluations }\end{array}$} & \multirow[b]{2}{*}{$\begin{array}{l}\text { Attributes of } \\
\text { target brand } \\
\text { (Calvé Varioprint } \\
\text { 3622) }\end{array}$} & \multicolumn{2}{|c|}{ Target well-specified } & \multirow[b]{2}{*}{ Sig. } & \multicolumn{2}{|c|}{ Target ambiguous } & \multirow[b]{2}{*}{$\begin{array}{l}\text { Sig. } \\
\text { (9) }\end{array}$} \\
\hline & & & $\begin{array}{c}\text { Pre-alliance } \\
\text { (no context) } \\
\text { mean } \\
\text { evaluations } \\
\text { (test values) } \\
(4)\end{array}$ & $\begin{array}{l}\text { Brand } \\
\text { alliance } \\
\text { mean } \\
\text { evaluations } \\
\text { (5) }\end{array}$ & & $\begin{array}{c}\text { Pre-alliance } \\
\text { (no context) } \\
\text { mean } \\
\text { evaluations } \\
\text { (test values) } \\
(7)\end{array}$ & $\begin{array}{c}\text { Brand } \\
\text { alliance } \\
\text { mean } \\
\text { evaluations } \\
\text { (8) }\end{array}$ & \\
\hline & & \multicolumn{7}{|c|}{ Positive valence } \\
\hline Reliability & 70.09 & Reliability & 60.00 & $69.02^{\mathrm{A}}$ & .000 & 54.40 & $67.46^{\mathrm{A}}$ & .000 \\
\hline Quality & 68.74 & Print quality & 59.05 & $75.29^{\mathrm{A}}$ & .000 & 56.00 & $68.41^{\mathrm{A}}$ & .000 \\
\hline Performance & 68.51 & Speed of printing & 67.62 & $78.04^{\mathrm{A}}$ & .000 & 56.40 & $69.21^{\mathrm{A}}$ & .000 \\
\hline Ease of use & 57.98 & Paper capacity & 70.95 & $80.20^{\mathrm{A}}$ & .000 & 56.80 & $59.27^{\mathrm{ns}}$ & .182 \\
\hline & & Ease of use & 64.76 & $74.12^{\mathrm{A}}$ & .000 & 52.00 & $70.16^{\mathrm{A}}$ & .000 \\
\hline Mean value & 66.33 & & 64.48 & 75.33 & & 55.12 & 66.90 & \\
\hline & & \multicolumn{7}{|c|}{ Negative valence } \\
\hline Reliability & 35.93 & Reliability & 60.00 & $49.85^{\mathrm{A}}$ & .000 & 54.40 & $52.08^{\mathrm{ns}}$ & .151 \\
\hline Quality & 36.30 & Print quality & 59.05 & $55.29^{\mathrm{ns}}$ & .081 & 56.00 & $56.36^{\mathrm{ns}}$ & .431 \\
\hline Performance & 35.68 & Speed of printing & 67.62 & $62.79^{\mathrm{A}}$ & .039 & 56.40 & $53.90^{\mathrm{ns}}$ & .092 \\
\hline \multirow[t]{2}{*}{ Ease of use } & 27.65 & Paper capacity & 70.95 & $60.44^{\mathrm{A}}$ & .000 & 56.80 & $54.68^{\mathrm{ns}}$ & .183 \\
\hline & & Ease of use & 64.76 & $52.85^{\mathrm{A}}$ & .000 & 52.00 & $51.19^{\mathrm{ns}}$ & .071 \\
\hline Mean values & 33.89 & & 64.48 & 56.24 & & 55.12 & 53.64 & \\
\hline
\end{tabular}

Note: A - assimilation; ns - no significant change 
Table 5 - Evaluation of the brand alliance - MANOVA results

\begin{tabular}{|c|c|c|c|c|c|c|c|c|}
\hline Source & Dependent Variable & $\begin{array}{l}\text { Sum of } \\
\text { Squares }\end{array}$ & $\mathrm{df}$ & $\begin{array}{l}\text { Mean } \\
\text { Square }\end{array}$ & $\mathrm{F}$ & Sig. & \multicolumn{2}{|c|}{ Mean values (std. dev) } \\
\hline & & & & & & & $\begin{array}{l}\text { Negative } \\
\text { valence }\end{array}$ & $\begin{array}{l}\text { Positive } \\
\text { valence }\end{array}$ \\
\hline \multirow[t]{6}{*}{ Valence } & Reliability & 18894.5 & 1 & 18894.5 & 69.01 & .000 & $50.96(16.58)$ & $68.24(16.64)$ \\
\hline & Print quality & 16259.0 & 1 & 16259.0 & 53.29 & .000 & $55.83(17.50)$ & $71.85(17.56)$ \\
\hline & Speed of printing & 14778.7 & 1 & 14778.7 & 48.77 & .000 & $58.34(17.44)$ & $73.62(17.50)$ \\
\hline & Paper capacity & 9458.6 & 1 & 9458.6 & 21.91 & .000 & $57.56(20.82)$ & $69.78(20.89)$ \\
\hline & Ease of use & 21353.6 & 1 & 21353.6 & 72.91 & .000 & $53.77(17.15)$ & $72.14(17.20)$ \\
\hline & & & & & & & $\begin{array}{c}\text { Target } \\
\text { ambiguous }\end{array}$ & $\begin{array}{l}\text { Target well- } \\
\text { specified }\end{array}$ \\
\hline \multirow[t]{5}{*}{ Information } & Reliability & 7.0 & 1 & 7.0 & .02 & .873 & $59.77(16.63)$ & $59.44(16.71)$ \\
\hline & Print quality & 534.6 & 1 & 534.6 & 1.75 & .187 & $62.39(17.55)$ & $65.29(17.49)$ \\
\hline & Speed of printing & 4976.4 & 1 & 4976.4 & 16.42 & .000 & $61.55(17.49)$ & $70.42(17.59)$ \\
\hline & Paper capacity & 11197.5 & 1 & 11197.5 & 25.94 & .000 & $57.02(20.88)$ & $70.32(20.99)$ \\
\hline & Ease of use & 19.7 & 1 & 19.7 & .06 & .795 & $62.68(17.19)$ & $63.24(17.29)$ \\
\hline \multirow[t]{5}{*}{ Valence * Information } & Reliability & 226.6 & 1 & 226.6 & .82 & .364 & & \\
\hline & Print quality & 1000.6 & 1 & 1000.6 & 3.28 & .071 & & \\
\hline & Speed of printing & .1 & 1 & .1 & .00 & .988 & & \\
\hline & Paper capacity & 3592.6 & 1 & 3592.6 & 8.32 & .004 & & \\
\hline & Ease of use & 732.1 & 1 & 732.1 & 2.50 & .115 & & \\
\hline
\end{tabular}




\section{Appendix}

Composition of industry experts

\begin{tabular}{|llll|}
\hline Expert & Industry & Position & Experience \\
\hline 1 & Telecommunications & Programme manager & $>5$ years \\
2 & Medical equipment & Marketing manager & $>10 \mathrm{yrs}$ \\
3 & Computing & Communications manager & $>10 \mathrm{yrs}$ \\
4 & Advertising & CEO & $>20 \mathrm{yrs}$ \\
5 & Retail & Project manager & $>10 \mathrm{yrs}$ \\
\hline
\end{tabular}

Distribution of evaluation of overall quality of known brand ally

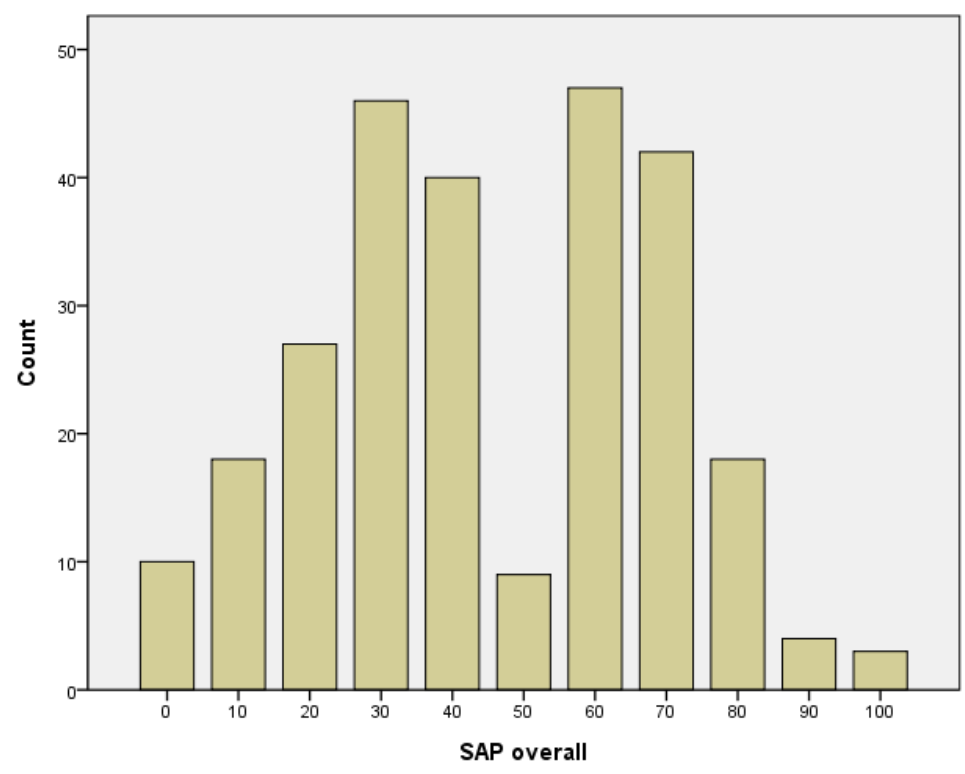




\section{Your Personal Production Assistant}

\section{Calvé}

\section{Varioprint 3622}

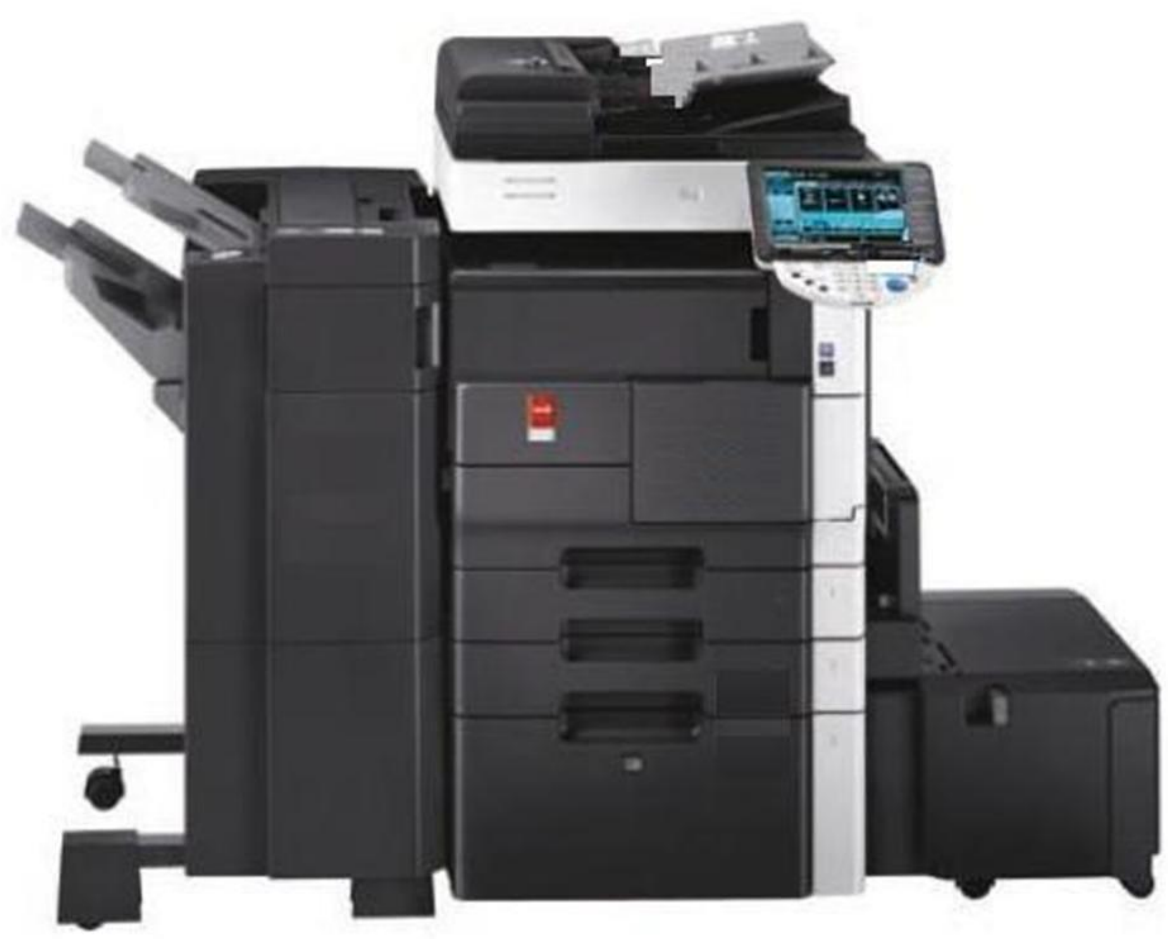

When you face tight deadlines for a wide variety of print applications, the last thing you need is a system that is difficult to use. The Calvé Varioprint 3622 combines superb ease of use with maximum reliability and durability for both quick office jobs and peak volumes-a genuine personal production assistant. The Calve's high definition photoreceptor technology ensures that quality is not compromised. Business-critical documents are handled efficiently and easily on the Calvé Varioprint 3622.

\section{The ultimate printer for business-} critical documents

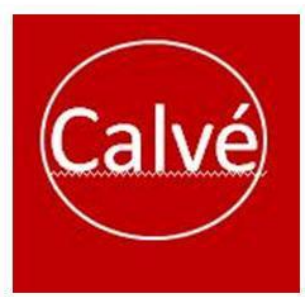




\section{Your Personal Production Assistant}

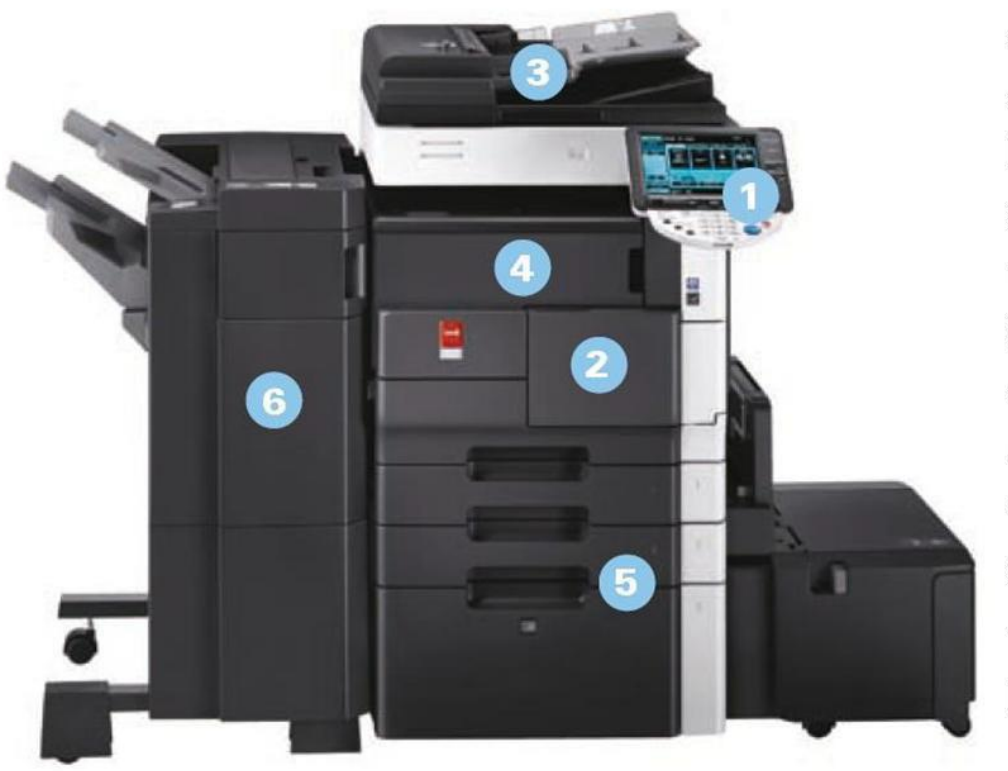

\section{Calvé}

\section{Varioprint 3622}

When you face tight

deadlines for a wide variety

of print applications, the

last thing you need is a

system that is difficult to

use. The Calvé Varioprint

3622 combines superb

ease of use with maximum

reliability and durability

for both quick office jobs

and peak volumes

- a genuine personal

production assistant.

Operator panel with touchscreen

The adjustable operator panel with programmable shortcut keys for

$600 \mathrm{MHz}$ processor and Standard 1 GB Memory

This system, with an optional 60GB hard disk, is designed to stand up to the most demanding use. It can handle all kinds of documents and
electronic inputs, ensuring compatielectronic inputs, ensuring compatibility with Postscript 3 and PCL $5 \mathrm{e} / 6$ and enables seamless integratiofinition definition photoreceptor technology ensures
mised.
Reversing automatic document feeder

60 sheet capacity feeder supports scanning at up to 70 original per
minute. New technology supports duplex speeds at $100 \%$ rated engin speed for maximum productivity

Environmentally sound

Using recycled materials and polymerised reduce environmental impact. Front -access toner door makes toner refilling easier. Electronic outputs fax, trp server, user box, email) help to reduce your company's paper output as needed.
Standard 2 paper trays and bypass tray

Up to 1000 sheet total capacity in size ranging from $\mathrm{A} 5$ to $\mathrm{A} 3.150$ sheet bypass tray automatically sense pape

\section{Embedded finisher}

The 3250 embedded finisher allows you to create 50 page stapled sets. th addition to multi-position stapling pling crease fold labels transparpling, crease fold, labels, transpar-

The ultimate printer for business-critical documents

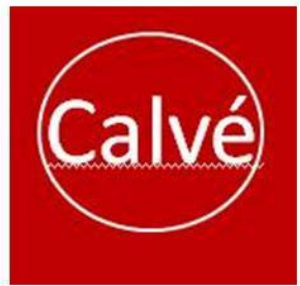




\section{REFERENCES}

Anderson, N. H. (1981). Foundations of information integration theory. New York: Academic Press.

Armstrong, J. S., \& Overton, T. S. (1977). Estimating non-response bias in mail surveys. Journal of Marketing Research, 14, 3, 396-402.

Baumgarth, C. (2004). Evaluations of co-brands and spill-over effects: Further empirical evidence. Journal of Marketing Communications. 10, 2, 115-131.

Bendixen, M., Bukasa, K. A., \& Abratt, R. (2004). Brand equity in the business-to-business market. Industrial Marketing Management, 33, 5, 371-380.

Bengtsson, A., \& Servais, P. (2005). Co-branding on industrial markets. Industrial Marketing Management, 34, 7, 706-713.

Bettman, J. R., Luce, M. F., \& Payne, W. J. (1998). Constructive consumer choice processes. Journal of Consumer Research, 25, 3, 187-217.

Bless, H., \& Greifeneder, F. (2009). Brands and successful brand extensions: A social psychology perspective on economic questions, in Wänke, M. (ed.) The Social Psychology of Consumer Behavior, (pp. 109-130), Philadelphia: Psychology Press.

Bless, H., \& Schwarz, N. (2010). Mental construal and the emergence of assimilation and contrast effects: The inclusion/exclusion model' in Mark, P. Z. (ed.) Advances in Experimental Social Psychology. (pp. 319-373). London: Academic Press.

Bluemelhuber, C., Carter, L. L., \& Lambe, C. J. (2007). Extending the view of brand alliance effects: An integrative examination of the role of country of origin. International Marketing Review, 24, 4, 427-443.

Brown, B. P, Bellenger, D. N., \& Johnston, W. J. (2007). The implications of business-tobusiness and consumer market differences for B2B branding strategy. Journal of Business and Market Management, 1, 3, 209 -229.

Brown, B. P., Zablah, A. R., Bellenger, D. N., \& Johnston, W. J. (2011). When do B2B brands influence the decision making of organizational buyers? An examination of the relationship between purchase risk and brand sensitivity. International Journal of Research in Marketing, 28, 3, 194-204.

Bucklin, L. P., \& Sengupta, S. (1993). Organizing successful co-marketing alliances. Journal of Marketing, 57, 2, 32-46.

Bunn, M. D. (1994). Key aspects of organizational buying: Conceptualization and measurement. Academy of Marketing Science, 22, 2, 160-169. 
Chartrand, T. L., van Baaren, R. B., \& Bargh, J. A. (2006). Linking automatic evaluation to mood and information processing style: Consequences for experienced affect, impression formation, and stereotyping, Journal of Experimental Psychology: General, $135,1,70-77$.

Cooke, A. D., \& Mellers, B. A. (1998). Multiattribute judgment: attribute spacing influences single attributes. Journal of Experimental Psychology: Human Perception and Performance, 24, 2, 496-504.

Cooke, S., \& Ryan, P. (2000). Brand alliances: from reputation endorsement to collaboration on core competencies. Irish Marketing Review, 13, 2, 36-41.

Cooke, A., Sujan, H., Sujan, M., \& Weitz, B. (2002). Marketing the unfamiliar: the role of context and item-specific information in electronic agent recommendations. Journal of Marketing Research, 39, 3, 488-497.

Dahlstrom, R., \& Dato-on, M. (2004). Business-to-business antecedents to retail co-branding. Journal of Business-to-Business Marketing, 11, 3, 1-20.

de Ruyter, K. \& Wetzels, M. (2000). The role of corporate Image and extension similarity in service brand extensions. Journal of Economic Psychology, 21, 6, 639-659.

Delplanque, S., Lavoieb, M. E., Hota, P., Silverta, L. \& Sequeira, H. (2004). Modulation of cognitive processing by emotional valence studied through event-related potentials in humans. Neuroscience Letters, 356, 1, 1-4.

Deshpande, R., \& Zaltman, G. (1987). A comparison of factors affecting use of marketing information in consumer and industrial firms. Journal of Marketing Research, 24, 1, 114-118.

Dhar, R., Nowlis, S. M., \& Sherman, S. J. (2000). Trying hard or hardly trying: An analysis of context effects in choice. Journal of Consumer Psychology, 9, 4, 189-200.

Dillman, D. A. (2007). Mail and Internet Surveys: The Tailored Design Method, $2^{\text {nd }}$ ed., Hoboken, NJ: John Wiley \& Sons.

Erevelles, S., Horton, V., \& Fukawa, N. (2008). Understanding B2C brand alliances between manufacturers and suppliers. Marketing Management Journal, 18, 2, 32-46.

Fang, X., \& Mishra, S. (2002), The effect of brand alliance portfolio on the perceived quality of an unknown brand, Advances in Consumer Research, 29, 519-520.

Fern, E. F. \& Brown, J. R. (1984). The industrial/consumer marketing dichotomy: a case of insufficient justification. Journal of Marketing, 48, 2, 68-77. 
Fiske, S. T. (1998). Stereotyping, Prejudice, and Discrimination. In Gilbert, D. T., Fiske, S. T., and Lindzey, G. (eds.) Handbook of Social Psychology, 2, 4th ed., (pp. 357-411). New York: McGraw Hill.

Gammoh, B. S., Voss, K. E., \& Chakraborty, G. (2006). Consumer evaluations of brand alliance signals. Psychology and Marketing, 23, 6, 465-486.

Gammoh, B. S., \& Voss, K. E. (2013). Alliance competence: The moderating role of valence of alliance experience. European Journal of Marketing, 47, 5/6, 964-986.

Ghosh, M., \& John, G. (2009). When should original equipment manufacturers use branded component contracts with suppliers? Journal of Marketing Research, 46, 5, 597-611.

Gilliland, D.I., \& Johnston, W.J. (1997). Toward a model of business-to-business marketing communications effects. Industrial Marketing Management, 26, 1, 15-29.

Greifeneder, R., \& Bless, H. (2010). The fate of activated information in impression formation: Fluency of concept activation moderates the emergence of assimilation versus contrast. British Journal of Social Psychology, 49, 2, 405-414.

Gummesson, E. and Polese, F. (2009). B2B is not an Island! Journal of Business and Industrial Marketing, 24, 5/6, 337-350.

Ha, Y., Park, S., \& Ahn, H. (2009). The influence of categorical attributes on choice context effects. Journal of Consumer Research, 36, 3, 463-477.

Heide, J. B., \& John, G. (1990). Alliances in industrial purchasing: the determinants of joint action in buyer-supplier relationships. Journal of Marketing Research, 27, 1, 24-36.

Helmig, B., Huber, J. A. and Leeflang, P. S. H. (2008) 'Co-branding: The State of the Art, Schmalenbach Business Review, 60, October, 359-377.

Henthorne, T. L., LaTour, M. S., \& Williams, A. J. (1993). How organizational buyers reduce risk. Industrial Marketing Management, 22, 1, 41-48.

Herbst, U., Schmidt, N., Ploder, S., \& Austen, V. (2012). What do we know about branding in the industrial context? A comprehensive status quo analysis. Proceedings of the Industrial Marketing and Purchasing Group Conference (IMP), Rome, Italy, September.

Herr, P. M. (1986). Consequences of priming: judgment and behavior. Journal of Personality and Social Psychology, 51, 6, 1106-1115.

Herr, P. M. (1989). Priming price: prior knowledge and context effects. Journal of Consumer Research, 16, 1, 67-75. 
Herr, P. M., Sherman, S. J., \& Fazio, R. H. (1983). On the consequences of priming: assimilation and contrast effects. Journal of Experimental Social Psychology, 19, 4, 323-340.

Higgins, E. T. (1996). Knowledge activation: Accessibility, applicability, and salience', in E.T. Higgins, A. W. Kruglanski (ed.), Social psychology: Handbook of basic principles, (pp. 133-168). New York: Guilford Press.

Huber, J., Payne, J. W., \& Puto, C. (1982). Adding asymmetrically dominated alternatives: violations of regularity and the similarity hypothesis. Journal of Consumer Research, 9, $1,90-98$.

Hutton, J. G. (1997). A study of brand equity in an organizational buying context. Journal of Product and Brand Management, 6, 6, 428-437. Industrial Marketing Management (2011). 40, 7, 1057-1216.

Jordan, K., \& English, P. W. (1989). Simultaneous sampling and length contrast. Perception \& Psychophysics, 46, 6, 546-54.

Kalafatis, S. P., Remizova, N., Riley, D., \& Singh, J. (2012). The differential impact of brand equity on B2B co-branding. Journal of Business \& Industrial Marketing, 27, 8, 623-634.

Keller, K. L., \& Aaker, D. (1992). The effects of sequential introduction of brand extensions. Journal of Marketing Research, 29, 1, 35-60.

Kohli, A. (1989). Determinants of influence in organizational buying: A contingency approach, Journal of Marketing; 53, 3, 50-65.

Lafferty, B. A., Goldsmith, R. E., \& Hult, G. T. M. (2004). The impact of the alliance on the partners: A look at cause-brand alliances. Psychology \& Marketing, 21, 7. 509-531.

Lafferty, B. and Goldsmith, R. (2005). Cause-Brand Alliances: Does the Cause Help the Brand or Does the Brand Help the Cause? Journal of Business Research, 58, 4, 423429.

Lee, M. P., \& Suk, K. (2010). Disambiguating the role of ambiguity in perceptual assimilation and contrast effects. Journal of Consumer Research, 36, 5, 890-897.

Leek, S., \& Christodoulides, G. (2011). Brands: Just for consumers? Industrial Marketing Management, 4, 7, 1060-1062.

Levin, A. (2002). Contrast and assimilation processes in consumers' evaluations of dual brands. Journal of Business and Psychology, 17, 1, 145-154. 
Levin, I. P., \& Levin, A. P. (2000). Modeling the role of brand alliances in the assimilation of product evaluations. Journal of Consumer Psychology, 9, 1, 43-52.

Lynch, J., \& de Chernatony, L. (2007). Winning Hearts and Minds: Business-to-Business Branding and the Role of the Salesperson. Journal of Marketing Management, 23, 1-2, 123-135.

Mao, H. \& Krishnan, H. S. (2006). Effects of prototype and exemplar fit on brand extension evaluations: A two-process contingency model. Journal of Consumer Research, 33, 1, 41-49.

Martin, L. L. (1986). Set/reset: use and disuse of concepts in impression formation. Journal of Personality and Social Psychology, 51, 3, 493-504.

Martin, L. L., Seta, J. J., \& Crelia, R. A. (1990). Assimilation and contrast as a function of people's willingness and ability to expend effort in forming an impression. Journal of Personality and Social Psychology, 59, 1, 27-37.

Meffert, M. F., Chung, S., Joiner, A. J., Waks, L. \& Garst, J. (2006). The effects of negativity and motivated information processing during a political campaign. Journal of Communication, 5, 1, 27-51.

Mendes, M. (2007). The effects of non-normality on Type III Error for comparing independent means. Journal of Applied Quantitative Methods, 2, 4, 444-454.

Meyers-Levy, J., \& Sternthal, B. (1993). A Two-Factor Explanation of Assimilation and Contrast Effects. Journal of Marketing Research, 30, 3, 359-368.

Michell, P., King, J., \& Reast, J. (2001). Brand values related to industrial products. Industrial Marketing Management, 30, 5, 415-425.

Mudambi, S. M. (2002). Branding importance in business-to-business markets - Three buyer clusters. Industrial Marketing Management, 31, 6, 525-533.

Mudambi, S. M., Doyle, P., \& Wong, V. (1997). An exploration of branding in industrial markets. Industrial Marketing Management, 26, 5, 433-446.

Nam, M., \& Sternthal, B. (2008). The effects of a different category context on target brand evaluations. Journal of Consumer Research, 35, 4, 668-679.

Nan, X. (2006). Affective cues and brand-extension evaluation: Exploring the influence of attitude toward the parent brand and attitude toward the extension ad. Psychology \& Marketing, 23, 7, 597-616.

Norris, D. G. (1993). Intel inside: branding a component in a business market. Journal of Business and Industrial Marketing, 8, 1, 14-24. 
Norris, C. E., \& Colman, A. M. (1996). Context effects of radio programming on cognitive processing of embedded advertisements. Applied Cognitive Psychology, 10, 6, 473-486.

Olsen, L. E., \& Lanseng, E. J. (2012). Brand Alliances: The Role of Brand Concept Consistency. European Journal of Marketing, 46, 9, 1108-1126.

Park, C. W., Jun, S. Y., \& Shocker, A. D. (1996). Composite branding alliances: an investigation of extension and feedback effects. Journal of Marketing Research, 33, 4, 453-466.

Park, J. E., \& Bunn, M. D. (2003). Organizational memory: A new perspective on the organizational buying process. Journal of Business \& Industrial Marketing, 18, 2/3, 237-255.

Rao, A. R., \& Ruekert, R. W. (1994). Brand alliances as signals of product quality. Sloan Management Review, 36, 1, 87-97.

Rao, A. R., Qu, L., \& Ruekert, R. W. (1999). Signaling unobservable product quality through a brand ally. Journal of Marketing Research, 36, 2, 258-268.

Robinson, P. J., Faris, C. W., \& Wind, Y. (1967). Industrial Buying and Creative Marketing. Boston, IL: Ally and Bacon, Inc.

Sen, S. (1998). Knowledge, information mode and the attraction effect. Journal of Consumer Research, 25, 1, 64-77.

Sherif, M., \& Hovland, C. I. (1961). Social judgment: Assimilation and contrast effects in communication and attitude change. Oxford: Yale University Press.

Simonin, B. L., \& Ruth, J. A. (1998). Is a company known by the company it keeps? Assessing the spillover effects of brand alliances on consumer brand attitudes. Journal of Marketing Research, 35, 1, 30-42.

Simonson, I., \& Tversky, A. (1992). Choice in context: trade-off contrast and extremeness aversion. Journal of Marketing Research, 29, 3, 281-295.

Souchon, A. L., Cadogan, J. W., Procter, D. B., \& Dewsnap, B. (2004). Marketing information use and organisational performance: the mediating role of responsiveness. Journal of Strategic Marketing, 12, 4, 231-242.

Spekman, R. E; \& Gronhaug, K. (1986). Conceptual and Methodological Issues in Buying Centre Research. European Journal of Marketing, 20, 7, 50-63.

Spekman, R. E., \& Stern, L. W (1979). Environmental uncertainty and buying group structure. Journal of Marketing, 43, 2, 54-64. 
Stapel, D. A., Koomen, W., \& Velthuijsen, A. S. (1998). Assimilation or contrast?:

Comparison relevance, distinctness, and the impact of accessible information on consumer judgements. Journal of Consumer Psychology, 7, 1, 1-24.

Stewart, K. J., \& Malaga, R. A. (2009). Contrast and assimilation effects on consumers' trust in Internet companies. International Journal of Electronic Commerce, 13, 3, 71-93.

Swaminathan, V., Fox, R. J., \& Reddy, S. K. (2001). The impact of brand extension introduction on choice. Journal of Marketing, 65, 4, 1-15.

Tiedens L. Z. \& Linton, S. (2001). Judgement under emotional certainty and uncertainty: The effects of specific emotions on information processing. Journal of Personality and Social Psychology, 81, 6, 973-988.

Todorović, D., (2010). Context effects in visual perception and their explanations. Review of Psychology, 17, 1, 17-32.

Voss, K., Gammoh, B., \& Chakraborty, G. (2006). Consumer evaluation of brand alliance signals. Psychology \& Marketing, 23, 6, 465-485.

Voss, K., Gammoh, B., \& Fang, X. (2012). How does a brand ally affect consumer evaluation of a focal brand. Psychology and Marketing, 29, 12, 929-940.

Walchli, S.B. (2007). The effects of between-partner congruity on consumer evaluations of co-branded products. Psychology and Marketing, 24, 11, 947-973.

Walker, W. R., Vogl, R. J., \& Thompson, C. P. (1997). Autobiographical memory: Unpleasantness fades faster than pleasantness over time. Applied Cognitive Psychology, $11,5,399-413$

Washburn, J. H., Till, B. D. \& Priluck, R. (2004). Brand alliance customer-based brandequity effects. Psychology and Marketing, 21, 7, 487-508.

Wilson, D. (2000). Why divide consumer and organizational buyer behaviour? European Journal of Marketing, 24, 7, 780-796.

Wilson, E., \& Woodside, A. (2001). Executive and consumer decision process: Increasing useful sense making by identifying similarities and departures. Journal of Business \& Industrial Marketing, 16, 5, 401-414.

Wind, Y. J. (2006). Blurring the lines: is there a need to rethink industrial marketing? Journal of Business and Industrial Marketing, 21, 7, 474-481.

Woodside, A. G. (2003). Middle-range theory construction of the dynamics of organizational marketing-buying behaviour. The Journal of Business \& Industrial Marketing, 18, 4/5, 309-33. 
Wright, P., \& Rip, P. (1980). Product class advertising effects on first-time buyers' decision strategies. Journal of Consumer Research, 7, 2, 776-788.

Zhu, R. J., \& Meyers-Levy, J. (2009). The influence of self-view on context effects: how display fixtures can affect product evaluations. Journal of Marketing Research, 66, 1, $37-45$.

Ziamou, P., \& Ratneshwar, S. (2003). Innovations in product functionality: when and why are explicit comparisons effective? Journal of Product Innovation Management, 67, 3, 49-61. 